\section{DNA barcoding and nutritional analysis as a tool for promoting the market of inland fish species}

\author{
Iolanda Venuti, ${ }^{1}$ Marina Ceruso, ${ }^{1}$ \\ Giuseppe Palma, ${ }^{2}$ Giorgio Smaldone, ${ }^{3}$ \\ Tiziana Pepe ${ }^{1}$
}

${ }^{1}$ Department of Veterinary Medicine and Animal Production, University of Naples Federico II, Naples; ${ }^{2}$ Assoittica Italia, Rome; ${ }^{3}$ Department of Agricultural Sciences, University of Naples Federico II, Naples, Italy

\begin{abstract}
The increasing world market demand for seafood requires an expansion of product categories available to consumers. Inland fish are usually considered having unmarked taste and are less appreciated by consumers; thus, they have low commercial value. Therefore, the marketing of the lake's fresh and processed fish is limited to the local market and consumers are currently uninformed and mistrustful about these species. In this study, six different fish species were caught in the Fondi lake (Lazio, central Italy): Anguilla anguilla, Tinca tinca, Carassius gibelio, Cyprinus carpio, Micropterus salmoides, Chelon ramada. All the samples were subjected to nutritional and DNA barcoding analysis. Moisture, protein, fat, carbohydrates, ash, and sodium content were measured. As regards the fatty acids profile, the most abundant were MUFAs with the highest value in Anguilla anguilla (45.97\%). Oleic acid (C18: $1 \mathrm{n} 9$ cis) was particularly high in Cyprinus carpio $(55.46 \%)$. The fraction of polyunsaturated fatty acids (PUFA) revealed a higher DHA content (C22: 6 n3) in Anguilla anguilla than the other species $(>12 \%)$ while Chelon ramada presented both higher EPA content (C 20: 5 n3) and total fraction of omega 3 PUFAs. Concerning molecular analysis, a 655 bp fragment of cytochrome C oxidase subunit I (COI) gene was successfully used for the identification at the species level using both BOLD and BLAST public databases. The present study gives the basis for improving the knowledge and promoting inland fish' market and traceability along the supply chain.
\end{abstract}

\section{Introduction}

The increase of the world market demand for fish products is due to the grow- ing public awareness and consumers' expectation concerning food security and quality (FAO, 2020). Fish is considered a high nutritional quality food with beneficial effects on human health for the favourable composition of proteins, minerals, vitamins, and essential fatty acids (FA) (Linhartová et al., 2018). In particular, it contains high levels of polyunsaturated fatty acids (PUFA), especially eicosapentaenoic (EPA) and docosahexaenoic (DHA) fatty acids, that were demonstrated to prevent coronary artery disease, cancers, and diabetes (Adámková et al., 2011; A. Watters and M. Edmonds, 2012; Linhartová et al., 2018). Besides, DHA has been considered essential for brain and eye development during pregnancy and early childhood (Özogul et al., 2007). The need to satisfy the growing market demand caused an over-exploitation of marine fish stocks and the massive importation from other countries (FAO, 2020). The longer supply lines of the fish chain promote the occurrence of different forms of fish frauds (Reilly, 2018) mainly regarding species substitution of expensive species with less valuable ones coming from abroad and mislabelling (Ceruso et al., 2019; Mascolo et al., 2019). In order to reduce the importation, strengthen the local economy, and improve the market of national products, it would be important to expand the knowledge about local seafood categories between consumers.

Inland fisheries, including fish captures in lakes, rivers, streams, canals, reservoirs, and other land-locked waters (FAO, 2018), are rapidly expanding on a global scale. In 2018, world total capture fisheries production in inland waters recorded their highestever catches, at over 12 million tonnes, ten of which are represented by freshwater fish (Aquaculture, 2020). Even though it has been proved that the provided source of essential FA is equivalent to marine fish (Özogul et al., 2007; Linhartová et al., 2018), the effective variety of inland species that can be caught is not properly exploited. In fact, in the common scenario, freshwater fish mainly coming from lakes are often considered having unmarked taste and are less appreciated by consumers, thus they have low commercial value (Özogul et al., 2007; Linhartová et al., 2018).

The current study aimed to improve the knowledge about the quality of some inland fish through their nutritional analysis and species identification in order to promote the trade and the traceability of species with market potential. Different inland specimens belonging to edible species (D.M. MIPAAF, 22 September 2017) have been caught in the Fondi lake, the largest coastal lake of Lazio, central Italy. In the lake there
Correspondence: Marina Ceruso, Department of Veterinary Medicine and Animal Production, University of Naples Federico II, via Federico Delpino 1, 80137, Naples, Italy. Tel.: +39.3478364407

E-mail: marina.ceruso@gmail.com

Key words: Freshwater fish, mtDNA, COI, fish frauds, nutritional composition.

Contributions: Conceptualization, TP, MC; methodology, MC, IV, GS; resources, TP, GP; writing - Original draft preparation, IV; writing - Review and editing, TP, MC, GS; supervision, TP, MC; funding acquisition, TP. All authors have read and agreed to the published version of the manuscript.

Conflict of interest: The authors declare no potential conflict of interest.

Funding: None.

Availability of data and materials: All data and materials are available within the text.

Received for publication: 18 December 2020 Accepted for publication: 6 July 2021

This work is licensed under a Creative Commons Attribution-NonCommercial 4.0 International License (CC BY-NC 4.0).

(C) Copyright: the Author(s), 2021

Licensee PAGEPress, Italy

Italian Journal of Food Safety 2021; 10:9565

doi:10.4081/ijfs.2021.9565

are more than 25 species of fish, some typical of freshwater and others of salt and brackish water, because of the communication with the sea through the canals of Sant'Anastàsia and Canneto (http://www.cittadifondi.it/?page id=560). In order to provide a full view of inland fish categories of the Fondi lake, both freshwater fish such as Cyprinus carpio, Tinca tinca, Carassius gibelio, Micropterus salmoides, euryhaline species such as Anguilla anguilla, and a typically marine but under-consumed fish such as Chelon ramada, were evaluated in this study.

\section{Materials and methods}

\section{Fish sampling}

Six fish species caught in the Fondi Lake (Lazio, central Italy, Figure 1) were collected: European eel (Anguilla anguilla, Linnaeus 1758), Tench (Tinca tinca, Linnaeus 1758), Prussian carp (Carassius gibelio, Bloch 1782), Common carp (Cyprinus carpio, Linnaeus 1758), Largemouth bass (Micropterus salmoides, 
Lacepède 1802), Thinlip grey mullet (Chelon ramada, Risso 1827). All the species were provided by local fishermen. Fish species were frozen at $-20{ }^{\circ} \mathrm{C}$ and transported in a sealed box to the Department of Veterinary Medicine and Animal Production of the University of Naples Federico II. The species were classified based on their anatomical and morphological characteristics and then stored at $80^{\circ} \mathrm{C}$ until nutritional and molecular analysis was performed.

\section{Nutritional analysis}

After preliminary desquamation and manual filleting of fish species, muscle tissues were subjected to chemical analysis according to the A.O.A.C. Official Method of Analysis (Association of Official Analytical Chemists Inc., Arlington, VA, USA, 2000). All tests were done in duplicate for each sample. The protein content was calculated with the Kjeldahl method (method 991.15); the lipid fraction was obtained by gravimetric method (method $960.30)$; the moisture was assessed by drying fish samples in an oven $\left(105^{\circ} \mathrm{C}\right.$ for 24h) (method 950.46); finally, the ash content was obtained using a muffle furnace at $600^{\circ} \mathrm{C}$ ( method 923.03$)$.

The remaining percentage from the analysis of the above-mentioned parameters was considered as a quote of carbohydrates. The sodium content was determined by argentometric titration with colorimetric indicator.

For the fatty acid profile, a transesterification with $2.5 \%$ sulfur: methanol solution $\left(\mathrm{H}_{2} \mathrm{SO}_{4}: \mathrm{MeOH}\right)$ was used (Watts and Browse, 2002). The fatty acid methyl esters (FAMEs) of the total fat content were analyzed by capillary gas chromatography, using a GC equipped with a flame ionization detector (FID) and a capillary column (Watts and Browse, 2002). The qualitative characteristics assessment of the lipid fraction was carried out by evaluating the atherogenicity index (AI) and the thrombogenicity index (TI) (Ulbricht and

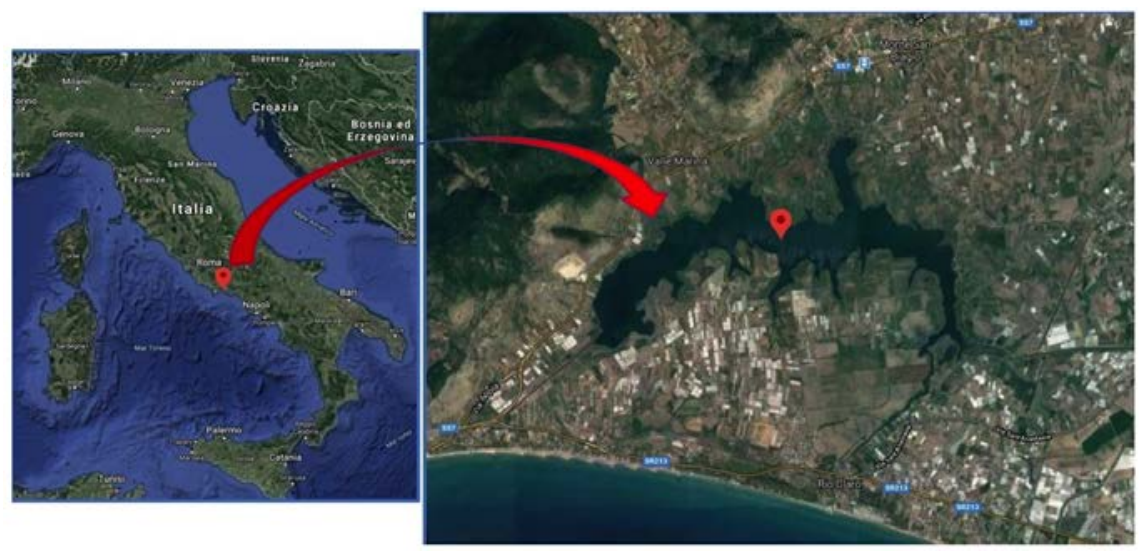

Figure 1. Fondi lake, Lazio, Italy.

Southgate, 1991; Garaffo et al., 2011). These values were calculated on the basis of the relative percentages of acidic fractions, according to the following formulas:

$$
\begin{gathered}
\mathrm{AI}=(\mathrm{C} 12: 0+4 \times \mathrm{C} 14: 0+\mathrm{C} 16: 0) / \\
{[(\Sigma \mathrm{MUFA}+\Sigma \text { PUFA }(\mathrm{n}-6) \text { and }(\mathrm{n}-3)]} \\
\mathrm{TI}=(\mathrm{C} 14: 0+\mathrm{C} 16: 0+\mathrm{C} 18: 0) /[(0.5 \times \\
\Sigma \mathrm{MUFA}+0.5 \times \Sigma \text { PUFA }(\mathrm{n}-6)+3 \times \\
\Sigma \text { PUFA }(\mathrm{n}-3)+(\mathrm{n}-3) /(\mathrm{n}-6)]
\end{gathered}
$$

\section{Total genomic DNA extraction}

Total genomic DNA was extracted from muscle tissue using the DNeasy Blood \& Tissue Kit (Qiagen, Hilden, Germany), according to the manufacturer's instructions. DNA concentration and purity were measured at the ratios of 260/2809 $\mathrm{nm}$ and 260/230 nm using Nanodrop (Thermo Fisher Scientific, Waltham, MA, USA). Electrophoretic analysis in 1\% agarose gel was performed to check the DNA quality.

\section{Primers selection, PCR amplifica- tion and sequencing}

A literature investigation was initially performed in order to compare fish's uni- versal primers used for the amplification of a long amplicon length (LAL) fragment from the mitochondrial cytochrome oxidase subunit I (COI) gene. All the universal primers considered in this research were reported in Table 1.

The complete mitogenome sequences of the selected freshwater fish species were provided by GenBank: Anguilla anguilla (NC_006531.1, Minegishi et al., 2005), Tinca tinca (NC_008648.1, Saitoh et al., 2006), 2006), Carassius gibelio (NC_014177.1, Liang et al., 2010), Cyprinus carpio (NC 001606.1, Chang et al, 1994), Micropterus salmoides (NC_008106.1, Broughton et al, 2006), Chelon ramada (complete mtDNA not reported). In order to find the most wellmatched primer sequences suitable for species identification, COI nucleotide sequences of the six species were aligned and analysed using MEGA X (Kumar et al., 2018).

PCR amplifications were carried out in a 2720 Thermal Cycler (Applied Biosystems, Thermo Fisher Scientific, Waltham, MA, USA) according to the protocol reported in Table 2 (Giusti et al., 2017,

Table 1. List of universal primers for fish species compared in this study.

\begin{tabular}{llll} 
Primer name & Primer sequences & Amplicon length (bp) & Reference \\
F (LCO1490) & GGTCAACAAATCATAAAGATATTGG & 658 & Folmer et al., 1994; Hebert et al., 2003; \\
F (HC02198) & TAAACTTCAGGGTGACCAAAAATCA & & Giusti et al., 2017 \\
\hline H (FISHCOILBC) & CTCAACYAATCAYAAAGATATYGGCAC & 655 & Handy et al., 2011; \\
H (FISHCOIHBC) & ACTTCYGGGTGRCCRAARATCA & & Giusti et al., 2017 \\
\hline COIF-ALT & ACAAATCAYAARGAYATYGG & 658 & Mikkelsen et al., 2005; \\
COIR-ALT & TTCAGGRTGNCCRAARAAYCA & & Giusti et al., 2017 \\
\hline FishF1 & TCAACCAACCACAAAGACATTGGCAC & 655 & Ward et al., 2005; Hubert et al., 2008; Lakra et al., 2016 \\
FishF2 & TCGACTAATCATAAAGATATCGGCAC & 655 & Ward et al., 2005 \\
\hline FishR1 & TAGACTTCTGGGTGGCCAAAGAATCA & 655 & Ward et al., 2005; Hubert et al., 2008; Lakra et al., 2016 \\
FishR2 & ACTTCAGGGTGACCGAAGAATCAGAA & 655 & Ward et al., 2005
\end{tabular}


modified). PCR products were confirmed by electrophoresis on a $2 \%$ agarose gel, stained with ethidium bromide and visualized via ultraviolet transillumination with Universal Hood II Gel Doc System (BioRad, USA). The amplicons were assessed by comparison with the standard marker GeneRuler 50 bp (Thermo Fisher Scientific, Waltham, MA, USA) and then purified using the QIAquick PCR Purification Kit (Qiagen, Hilden, Germany). Amplified products sequencing was carried out by Bio-Fab Research (Rome, Italy). The obtained sequences were aligned using ClustalW integrated into MEGA X (Kumar et al., 2018).

\section{Data analysis}

All the gene sequences were submitted to both BLAST analysis (GenBank) and Identification System (IDs) Species Level Barcode Records of BOLD.

The highest identity percentages obtained within the first 100 top match records by BLAST and ID's query were recorded. Species identification with BLAST analysis was based on maximum scores with matching sequences corresponding to $>98 \%$ identity and coverage, and alignment values $\mathrm{E}=0.0$. As for BOLD, specimens were considered identified at species level when the matches showed at least $98 \%$ identity with the reference sequences (Barbuto et al., 2010, Armani et al. 2015). The results obtained using molecular analysis were then compared to the morphological and anatomical identification of the caught fish species made by experts.

\section{Results}

\section{Nutritional analysis}

The chemical composition of each species collected in this study is presented in Table 3.

The percentage of protein (11.8-18.9\%), carbohydrates (0.1-0.9\%) and ash (0.9$2.8 \%$ ) varied between species. Tinca tinca, Carassius gibelio and Cyprinus carpio were the species with the highest levels of protein $(>17 \%)$ while Anguilla anguilla showed the lowest content $(11.8 \%)$. Different values were also found in the lipid content and moisture: in particular Tinca tinca was found to be the species with the lowest fat content $(0.5 \%)$ whereas Anguilla anguilla exceeded $23 \%$.

The results of fatty acid composition showed that the class of monounsaturated fatty acids (MUFA) is the most represented, with the highest value in Anguilla anguilla
(45.97\%). Within the MUFA fraction, the highest percentage of acidic content is given by oleic acid (C18: $1 \mathrm{n} 9 \mathrm{cis})$, particularly high in Cyprinus carpio (55.46\%).

The saturated fatty acid (SFA) fraction was not very different between species (21$27 \%$ ). However, within the class, there are differences relative to single fatty acids. A higher content of myristic acid (C14: 0$)$ and stearic acid (C18: 0) was found in Chelon ramada $(4.39 \%)$ and Carassius gibelio $(6.70 \%)$. As regards the fraction of polyunsaturated fatty acids (PUFA), Anguilla anguilla presented a higher DHA content (C22: $6 \mathrm{n} 3$ ) than the other species $(>12 \%)$ while Chelon ramada presented a higher EPA content (C20: $5 \mathrm{n} 3)(\sim 12 \%)$ and a higher total fraction of omega 3 PUFAs. The increase in this value is mainly due to a higher content of alpha-linoleic acid (ALA C18: $3 \mathrm{n} 3$ ) and stearidonic acid (18: $4 \mathrm{n} \mathrm{3)}$.

\section{Total genomic DNA extraction and primers selection}

From all the fish species, a good quantity of DNA $(\sim 40 \mathrm{ng} / \mu \mathrm{l})$ was extracted. The spectrophotometric analysis confirmed high yield and quality, with ratios of A260/A280 $\mathrm{nm}$ and A260/A230 nm >1.8 in all the samples. After the comparison of sequences and the evaluation of the number of matches, two pairs of primers were selected: $F$

Table 2. Amplification protocols and programs for each couple of primers selected in this study.

\begin{tabular}{lcc} 
& $\mathrm{F}$ & $\mathrm{H}$ \\
Buffer 10x & $2 \mu \mathrm{l}$ & $2 \mu \mathrm{l}$ \\
MgCl2 & $1.5 \mathrm{mM}$ & $1.5 \mathrm{mM}$ \\
\hline dNTPs & $200 \mathrm{\mu M}$ & $200 \mu \mathrm{M}$ \\
Taq polymerase & $1.25 \mathrm{U}$ & $1.25 \mathrm{U}$ \\
\hline BSA & $25 \mathrm{ng} / \mu \mathrm{l}$ & $25 \mathrm{ng} / \mu \mathrm{l}$ \\
DNase free water & $200 \mathrm{nM}$ & $300 \mathrm{nM}$ \\
\hline Primers concentration & $\sim 40 \mathrm{ng} / \mu \mathrm{l}$ & $\sim 40 \mathrm{ng} / \mu \mathrm{l}$ \\
Total DNA & $94^{\circ} \mathrm{C}$ for $3^{\prime}$ & $94^{\circ} \mathrm{C}$ for $3^{\prime}$ \\
\hline Taq activation & 35 & 45 \\
N. of cycles & $95^{\circ} \mathrm{C}$ for $\mathbf{1}^{\prime}$ & $94^{\circ} \mathrm{C}$ for $30^{\prime \prime}$ \\
\hline Denaturation & $50^{\circ} \mathrm{C}$ for $\mathbf{l}^{\prime}$ & $55^{\circ} \mathrm{C}$ for $20^{\prime \prime}$ \\
Annealing & $72^{\circ} \mathrm{C}$ for $30^{\prime \prime}$ & $72^{\circ} \mathrm{C}$ for $40^{\prime \prime}$ \\
\hline Extension & $72^{\circ} \mathrm{C}$ for $7^{\prime}$ & $72^{\circ} \mathrm{C}$ for $10^{\prime}$ \\
Final elongation & &
\end{tabular}

Table 3. Nutritional values (\%) of sampled fish species for $100 \mathrm{~g}$ of muscle tissue.

\begin{tabular}{|c|c|c|c|c|c|c|}
\hline & Anguilla anguilla & Tinca tinca & Carassius gibelio & Cyprinus carpio & Micropterus salmoides & Chelon ramada \\
\hline Moisture & 61.5 & 78.5 & 72.5 & 71.5 & 80.5 & 73.4 \\
\hline Protein & 11.8 & 17.9 & 18.9 & 17.5 & 14.7 & 15.8 \\
\hline Fat & 23.7 & 0.5 & 7.1 & 8.4 & 3.3 & 6.8 \\
\hline Carbohydrates & 0.25 & 0.9 & 0.1 & 0.2 & 0.1 & 0.7 \\
\hline Ash & 2.1 & 1.4 & 0.9 & 1.7 & 0.9 & 2.8 \\
\hline Sodium & 0.65 & 0.8 & 0.5 & 0.7 & 0.5 & 0.5 \\
\hline
\end{tabular}


(LCO1490 - HCO2198) and H (for FISHCOILBC - rev_ FISHCOILBC). Melting temperature $(\mathrm{Tm})$, nucleotide composition, secondary structure, self-annealing, and inter-primer binding, were verified using Multiple Primer Analyzer (Thermo Fisher Scientific, Waltham, MA, USA). The primers' set is reported in Table 4.

\section{PCR amplification and sequencing}

The "H primer set" successfully amplified the target region of $C O I$, giving highintensity bands (Figure 2). The "F primer set" failed to bind to the target DNA of fish samples, requiring an implementation of the amplification protocol provided by the literature. At first, annealing temperature was increased from $40^{\circ} \mathrm{C}$ up to $55^{\circ} \mathrm{C}$ but there was no amplification of the $\mathrm{COI}$ fragment. Therefore, the temperature was set to $50^{\circ} \mathrm{C}$, giving sequences length of $\sim 655 \mathrm{bp}$, corresponding to $100 \%$ amplification of the expected amplicons. PCR products were all sequenced with a $100 \%$ rate.

\section{Data analysis}

As for BOLD ID's results, Anguilla anguilla, Tinca tinca, Cyprinus carpio and Micropterus salmoides were identified at the species level with a $100 \%$ match whereas Carassius gibelio and Chelon ramada were identified only at genus level, because of the high sequence similarity. In particular, Carassius gibelio presented a $100 \%$ match with both Carassius gibelio, Carassius auratus and Carassius carassius, whereas Chelon ramada presented a match of $100 \%$ similarity with Chelon saliens and 99.84\% similarity with Mugil cephalus. It has been possible to identify this last two fish at species level using BLAST analysis, with the maximum score with matching sequences corresponding to $100 \%$ identity and coverage, and alignment values $\mathrm{E}=0.0$. The combination of BLAST and BOLD ID's results, compared to morphological features, confirm the expected species identity.

\section{Discussion}

In 2019, the EU was the world's sec- ond-largest trader of fishery and aquaculture products after China (EUMOFA, 2020). Italy is one of the largest markets for these products in Europe, and the country covers most of the demand through imports (Eurofish International Organisation; MIPAAF, 2020).

Inland fish products still play a marginal role in this scenario. The marketing of the lake's fresh and processed fish is generally limited to the local market.

The nutritional analysis carried out in this study showed that Tinca tinca, Carassius gibelio and Cyprinus carpio presented a good level of protein and quite low-fat content (Table 3) compared to marine fish products (Özogul et al., 2007; Fernandes et al., 2014). In particular, Tinca tinca was the species with the highest protein content $(17.9 \%)$ and the lowest fat percentage $(0.5 \%)$. Therefore, this species could be considered as an interesting alternative to marine fish such as Merluccius merluccius (17\% protein and $0.3 \%$ fat) (CREA, 2016) in low fat diet designed to reduce calorie intake, maintaining high levels of protein. As concern fatty acid profile, oleic acid, is particularly expressed in Cyprinus carpio. There is a direct relationship between the consumption of SFAs in

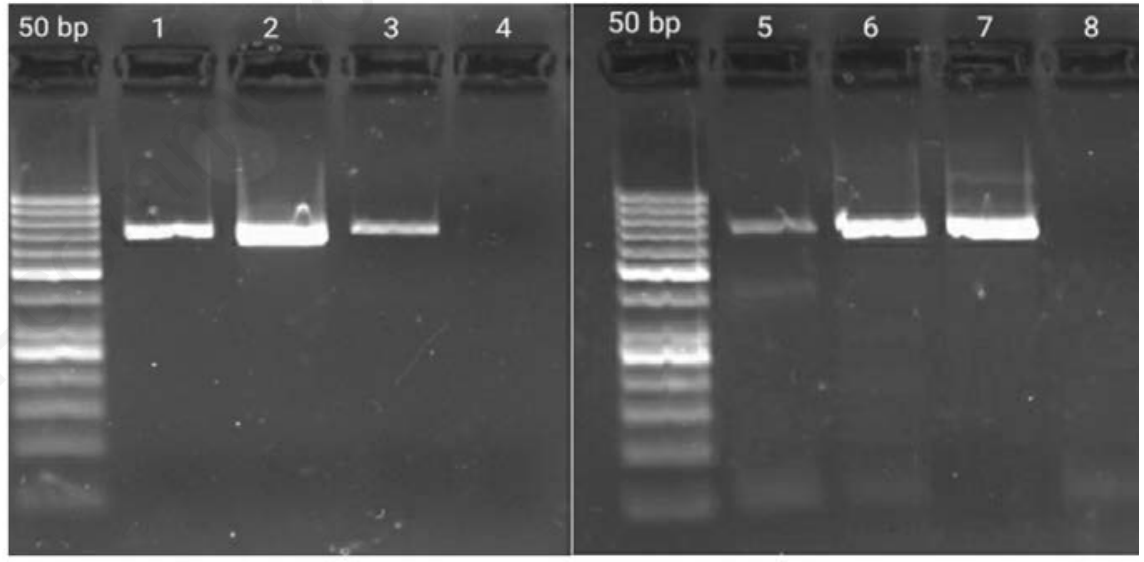

Figure 2. PCR amplification of COI fragment with "H primer set". Electrophoresis on $2 \%$ agarose gel. Control ladder: 50 bp. Lane 1: Chelon ramada. Lane 2: Cyprinus carpio. Lane 3: Carassius gibelio. Lane 5: Anguilla anguilla. Lane 6: Tinca tinca. Lane 7: Micropterus salmoides. Lane 4, 8: negative control. the diet and the risk of cardiovascular discholesterol levels associated with LDL (low-density lipoprotein) (Briggs et al., 2017; Wang et al., 2017). The European Food Safety Authority (EFSA) recommends replacing SFAs in the diet with an equal amount of MUFA to reduce blood levels of LDL cholesterol (EFSA, 2010). Among the PUFAs, the omega 3 series play an important role in the prevention of serious human diseases, particularly long-chain ones, such as EPA and DHA (A. Watters and M. Edmonds, 2012; Briggs et al., 2017), whose values are best expressed in Anguilla anguilla and Chelon ramada, respectively. The quality of the lipid fraction evaluated on the basis of indices of atherogenicity (AI) and thrombogenicity (TI) proved to be remarkable in all the species analysed, in particular Anguilla anguilla, Chelon rama$d a$ and Cyprinus carpio. It is important to note that nutritional values of these species are beneficial in comparison with a lot of imported freshwater or marine fish species. Particularly, Pangasius hypophthalmus, Oncorhynchus mykiss and Oreochromis niloticus showed a SFA content of $42.18 \%$, $25.69 \%$ and $38.94 \%$ respectively (Luczynska et al., 2014). Furthermore, also eases due to the increase in the blood of

Table 4. Selected primers resulting suitable for the identification of the species Anguilla anguilla, Tinca tinca, Carassius gibelio, Cyprinus carpio, Micropterus salmoides, Chelon ramada.

\begin{tabular}{|c|c|c|c|c|c|c|c|c|c|c|}
\hline $\mathbf{N}$ & Primer name & Amplicon length (bp) & $5^{\prime}-3^{\prime}$ sequence & $\mathrm{Tm}^{\circ} \mathrm{C}$ & CG\% & $\mathrm{nt}$ & A & $\mathrm{T}$ & C & G \\
\hline \multirow[t]{2}{*}{$\mathrm{F}$} & LCO1490 & 658 & GGTCAACAAATCATAAAGATATTGG & 56.4 & 32.0 & 25 & 11.0 & 6.0 & 3.0 & 5.0 \\
\hline & HC02198 & & TAAACTTCAGGGTGACCAAAAAATCA & 58.5 & 34.6 & 26 & 12.0 & 5.0 & 5.0 & 4.0 \\
\hline \multirow[t]{2}{*}{$\mathrm{H}$} & for_FISHCOILBC & 655 & CTCAACYAATCAYAAAGATATYGGCAC & 61.2 & 38.9 & 27 & 11.0 & 5.5 & 7.5 & 3.0 \\
\hline & rev_FISHCOILBC & & GTGCCYATATCTTTYTGATTYGTTGAG & 61.2 & 38.9 & 27 & 4.0 & 12.5 & 4.5 & 6.0 \\
\hline
\end{tabular}


some marine fish such as Gadus morhua and Platichthys flesus presented a higher SFA content $(32.77 \%$ and $28.72 \%$, respectively) (Luczynska et al., 2014) compared to the examined species (21-27\%). Considering the favourable unsaturated fatty acids amounts (especially MUFAs) of our studied specimens, they could be included in diets aimed at controlling cholesterolemia.

Our results reveal that $C O I$ barcode was successful in identifying the selected specimens, proving to be a powerful tool for species identification. In particular, Carassius gibelio is difficult to differentiate from its congeneric species Carassius carassius, also in the whole fish because of their high morphological similarities (Guardone et al., 2017). Molecular tools are also particularly important when a fish product loses its anatomical features after industry processing (Ceruso et al., 2020).

The choice of the "H primers set" was found to be effective for the amplification of all the selected species. As regards the " $F$ primers set", recent studies show an amplification rate in fish species of just $34.7 \%$, with no amplification in some freshwater fish such as Cyprinus carpio (Giusti et al., 2017). Our results demonstrated that increasing the annealing temperature from $40^{\circ} \mathrm{C}$ to $50^{\circ} \mathrm{C}$, the expected amplicon is obtained for all the six species.

BLAST and BOLD analysis of the COI sequences make it possible to recognize and identify a vast number of fish at the species level. Both databases should be used for more accurate sequence comparison and analysis.

\section{Conclusions}

The consumer is currently accustomed to the stronger flavour of marine species, at the expense of inland ones, also because of their higher availability on the market. The present work showed that the nutritional profile of some freshwater fish could be equivalent to marine fish species, especially regarding the fatty acids content. Furthermore, the establishment of a DNA barcoding protocol to identify inland fish could assess their traceability along the supply chain, as defined by Regulation (EU) 1169/2011 and Regulation (EU) 1379/2013, enforcing food safety system and contributing to a more transparent and safer fish market.

Inland fish, especially species with high nutritional properties, have interesting market potential and can represent a valid and sustainable alternative to the over-exploitation of fish stocks, and importations improving the national and the local economy. The change in eating habits and the use of a flavoursome way of cooking able to enrich the unmarked taste of inland species could direct the consumer towards a more informed purchase of the local product, taking into account also the lower price compared to the most commercialized marine fish species.

\section{References}

AOAC, 2000. Official Methods of Analysis, 17th ed. Method 976.18. Association of Official Analytical Chemists, Gaithersburg, MD, USA.

A.Watters C, M. Edmonds C, 2012. A Cost Analysis of EPA and DHA in Fish, Supplements, and Foods. J Nutr Food Sci 2:8.

Adámková V, Kacer P, Mraz J, Suchanek P, Pickova J, Králova Lesná I, Skibova J, Kozak P, Maratka V, 2011. The consumption of the carp meat and plasma lipids in secondary prevention in the heart ischemic disease patients. Neuroendocrinol Lett 32:17-20.

Aquaculture ETDEL, 2020. FAO Yearbook. Fishery and Aquaculture Statistics 2018/FAO annuaire. Available online: http:/www.fao.org/documents/card/en/ c/cb1213t/.

Armani A, Guardone L, Castigliego L, D’Amico P, Messina A, Malandra R, Gianfaldoni D, Guidi A, 2015. DNA and Mini-DNA barcoding for the identification of Porgies species (family Sparidae) of commercial interest on the international market. Food Control 50:589-96.

Barbuto M, Galimberti A, Ferri E, Labra M, Malandra R, Galli P, Casiraghi M, 2010. DNA barcoding reveals fraudulent substitutions in shark seafood products: The Italian case of 'palombo' (Mustelus spp.). Food Res Int 43:376-81.

Briggs M, Petersen K, Kris-Etherton P, 2017. Saturated Fatty Acids and Cardiovascular Disease: Replacements for Saturated Fat to Reduce Cardiovascular Risk. Healthcare 5:29.

Broughton RE, Reneau PC, 2006. Spatial Covariation of Mutation and Nonsynonymous Substitution Rates in Vertebrate Mitochondrial Genomes. Mol Biol Evol 23:1516-24.

Ceruso M, Mascolo C, Anastasio A, Pepe T, Sordino P, 2019. Frauds and fish species authentication: Study of the complete mitochondrial genome of some Sparidae to provide specific barcode markers. Food Control 103:36-47.

Ceruso M, Mascolo C, De Luca P, Venuti I, Smaldone G, Biffali E, Anastasio A,
Pepe T, Sordino P, 2020. A rapid method for the identification of fresh and processed pagellus erythrinus species against frauds. Foods 9:1397.

CREA Centro di ricerca Alimenti e Nutrizione, 2016. Tabelle di composizione degli alimenti. Available online: https://www.alimentinutrizione.it/tabell e-nutrizionali/121410.

EFSA, 2010. Scientific Opinion on Dietary Reference Values for fats, including saturated fatty acids, polyunsaturated fatty acids, monounsaturated fatty acids, trans fatty acids, and cholesterol. EFSA J 8:1461.

EUMOFA, 2020. The EU Fish Market 2020. Luxembourg: Publications Office of the European Union.

Eurofish International Organisation. Rome, IT. Available online: https://www.eurofish.dk/italy.

European Parliament and Council of the European Union, 2011. Regulation (EU) No 1169/2011 of the European Parliament and of the Council of 25 October 2011 on the provision of food information to consumers, amending Regulations (EC) No 1924/2006 and (EC) No 1925/2006 of the European Parliament and of the Council, and repealing Commission Directive 87/250/EEC, Council Directive 90/496/EEC, Commission Directive 1999/10/EC, Directive 2000/13/EC of the European Parliament and of the Council, Commission Directives 2002/67/EC and 2008/5/EC and Commission Regulation (EC) No $608 / 2004$. In: Official Journal, L 304/18, 22/11/2011.

European Parliament and Council of the European Union, 2013. Regulation (EU) No 1379/2013 of the European Parliament and of the Council of 11 December 2013 on the common organisation of the markets in fishery and aquaculture products, amending Council Regulations (EC) No 1184/2006 and (EC) No 1224/2009 and repealing Council Regulation (EC) No 104/2000. In: Official Journal, L 354/1, 28/12/2013.

FAO, 2018. Review of the state of the world fishery resources: inland fisheries. Rome, IT. Available online: http://www.fao.org/3/ca0388en/CA038 8EN.pdf.

FAO, 2020. The State of World Fisheries and Aquaculture 2020. Sustainability in action. Rome, IT. Available online: https://doi.org/10.4060/ca9229en.

Fernandes CE, Vasconcelos MADS, De Almeida Ribeiro M, Sarubbo LA, Andrade SAC, Filho ABDM, 2014. 
Nutritional and lipid profiles in marine fish species from Brazil. Food Chem 160:67-71.

Folmer O, Black M, Hoeh W, Lutz R, Vrijenhoek R, 1994. DNA primers for amplification of mitochondrial

cytochrome c oxidase subunit I from diverse metazoan invertebrates. Mol Marine Biol Biotechnol 3:294-9.

Garaffo MA, Vassallo-Agius R, Nengas Y, Lembo E, Rando R, Maisano R, Dugo G, Giuffrida D, 2011. Fatty Acids Profile, Atherogenic (IA) and Thrombogenic (IT) Health Lipid Indices, of Raw Roe of Blue Fin Tuna (Thunnus thynnus L.) and Their Salted Product "Bottarga". Food Nutr Sci 2:736-43.

Giusti A, Tinacci L, Sotelo CG, Marchetti M, Guidi A, Zheng W, Armani A, 2017. Seafood Identification in Multispecies Products: Assessment of 16SrRNA, cytb, and COI Universal Primers' Efficiency as a Preliminary Analytical Step for Setting up Metabarcoding Next-Generation Sequencing Techniques. J Agric Food Chem 65:2902-12.

Guardone L, Tinacci L, Costanzo F, Azzarelli D, D’Amico P, Tasselli G, Magni A, Guidi A, Nucera D, Armani A, 2017. DNA barcoding as a tool for detecting mislabeling of fishery products imported from third countries: An official survey conducted at the Border Inspection Post of Livorno-Pisa (Italy). Food Control 80:204-16.

Handy SM, Deeds JR, Ivanova NV, Hebert PD, Hanner RH, Ormos A, Weigt LA, Moore MM, Yancy HF, 2011. A singlelaboratory validated method for the generation of DNA barcodes for the identification of fish for regulatory compliance. J AOAC Int 94:201-10.

Hebert PD, Ratnasingham S, de Waard JR,
2003. Barcoding animal life: cytochrome c oxidase subunit 1 divergences among closely related species. Proc Biol Sci 270:S96-9.

Hubert N, Hanner R, Holm E, Mandrak NE, Taylor E, Burridge M, Watkinson D, Dumont P, Curry A, Bentzen P, Zhang J, April J, Bernatchez L, 2008. Identifying Canadian freshwater fishes through DNA barcodes. PLoS One 3:e2490.

Kumar S, Stecher G, Li M, Knyaz C, Tamura K, 2018. MEGA X: Molecular Evolutionary Genetics Analysis across Computing Platforms. Mol Biol Evol 35:1547-9.

Lakra WS, Singh M, Goswami M, Gopalakrishnan A, Lal KK, Mohindra V, Sarkar UK, Punia PP, Singh K V., Bhatt JP, Ayyappan S, 2016. DNA barcoding Indian freshwater fishes. Mitochondrial DNA Part A DNA Mapping Seq Anal 27:4510-7.

Linhartová Z, Krejsa J, Zajíc T, Másílko J, Sampels S, Mráz J, 2018. Proximate and fatty acid composition of 13 important freshwater fish species in central Europe. Aquac Int 26:695-711.

Luczynska J, Paszczyk B, Luczynski MJ, 2014. Fatty acid profiles in marine and freshwater fish from fish markets in northeastern Poland. Arch. Polish Fish 22:181-8.

Mascolo C, Ceruso M, Sordino P, Palma G, Anastasio A, Pepe T, 2019. Comparison of mitochondrial DNA enrichment and sequencing methods from fish tissue. Food Chem 294:333-8.

Mikkelsen PM, Bieler R, Kappner I, Rawlings TA, 2006. Phylogeny of Veneroidea (Mollusca: Bivalvia) based on morphology and molecules. Zool J Linn Soc 148:439-521.

Minegishi Y, Aoyama J, Inoue JG, Miya M, Nishida M, Tsukamoto K, 2005. Molecular phylogeny and evolution of the freshwater eels genus Anguilla based on the whole mitochondrial genome sequences. Mol Phylogenet Evol 34:134-46.

MIPAAF, BMTI S.c.p.A., 2020. Annuario sul mercato ittico 2019. Rome, IT. Available online: https://www.bmti.it/.

Özogul Y, Özogul F, Alagoz S, 2007. Fatty acid profiles and fat contents of commercially important seawater and freshwater fish species of Turkey: A comparative study. Food Chem 103:217-23.

Reilly A, 2018. Overview of food fraud in the fisheries sector. FAO Fisheries and Aquaculture Circular No. 1165. Rome, IT. Available online: http://www. fao.org/3/I8791EN/i8791en.pdf.

Saitoh K, Sado T, Mayden RL, Hanzawa N, Nakamura K, Nishida M, Miya M, 2006. Mitogenomic evolution and interrelationships of the cypriniformes (Actinopterygii: Ostariophysi): The first evidence toward resolution of higherlevel relationships of the world's largest freshwater fish clade based on 59 whole mitogenome sequences. J Mol Evol 63:826-41.

Ulbricht TL, Southgate DA, 1991. Coronary heart disease: seven dietary factors. Lancet 338:985-92.

Wang J, Zhang L, Zhang Q, Zhou M, Wang $\mathrm{X}, 2017$. Comparative mitogenomic analysis of mirid bugs (Hemiptera: Miridae) and evaluation of potential DNA barcoding markers. Peer-J 5:e3661.

Ward RD, Zemlak TS, Innes BH, Last PR, Hebert PDN, 2005. DNA barcoding Australia's fish species. Philos Trans R Soc B Biol Sci 360:1847-57.

Watts JL, Browse J, 2002. Genetic dissection of polyunsaturated fatty acid synthesis in Caenorhabditis elegans. Proc Natl Acad Sci USA 99:5854-9. 